\title{
Mechanical Circulatory Support as an Alternative Solution in Circumstances Leading to a Shortage of Organ Donors
}

\author{
Yuriy Pya ${ }^{1}$, Makhabbat Bekbossynova ${ }^{1}$, Assel Medressova ${ }^{1}$, Serik Bekbossynov ${ }^{1}$, Saltanat \\ Andossova $^{1}$, Roman Salov ${ }^{1}$, Rymbai Kaliyev ${ }^{1}$, Aigerim Abdiorazova ${ }^{1}$, and Piet Jansen ${ }^{2}$ \\ ${ }^{1}$ National Research Cardiac Surgery Center \\ ${ }^{2}$ CARMAT
}

November 30, 2020

\begin{abstract}
Background. Mechanical circulatory support (MCS) has been applied as an effective therapy for patients with end stage heart failure (HF). The existing donor organ shortage issue in Kazakhstan, and hence long waiting times, have resulted in left ventricular assist device (LVAD) implantation being the predominant surgical treatment method for this condition. The purpose of this study is to analyze clinical outcomes of MCS program data in our Center. Methods. This study involves a retrospective analysis of 324 patients with different types of implantable MCS including LVAD ( $\mathrm{n}=319$ ), fully implantable LVAD (FIVAD, $n=2$ ), and total artificial heart (TAH, $n=3$ ). FIVAD and TAH cases were analyzed separately from other VAD types due to their small numbers. Results. Initially, LVADs were implanted as bridge-to-transplant (BTT) in 214 (67.1\%) of patients and as a destination therapy (DT) in $105(32.9 \%)$ cases, but only 30 (9.4\%) patients proceeded to transplant. The overall survival rate of all LVAD patients at years $1,2,3$, and 4 was $84.3 \%, 69.7 \%, 62.8 \%$, and $52.5 \%$, respectively. The distance from the clinic (Nur-Sultan) to patients' cities of residence (average $1015 \pm 668$ kilometers) was not associated with patient survival. Conclusions. Developing MCS programs is crucial in providing care for patients with HF. Using LVAD as DT produced satisfactory outcomes with favorable survival rates, which are comparable to the outcomes reported in other studies. Further trials are needed to investigate the results of TAH and FIVAD implantation in order to establish them as an acceptable alternative treatment to heart transplantation.
\end{abstract}

\section{Hosted file}

Manuscript.pdf available at https://authorea.com/users/379860/articles/496077-mechanicalcirculatory-support-as-an-alternative-solution-in-circumstances-leading-to-a-shortageof-organ-donors 


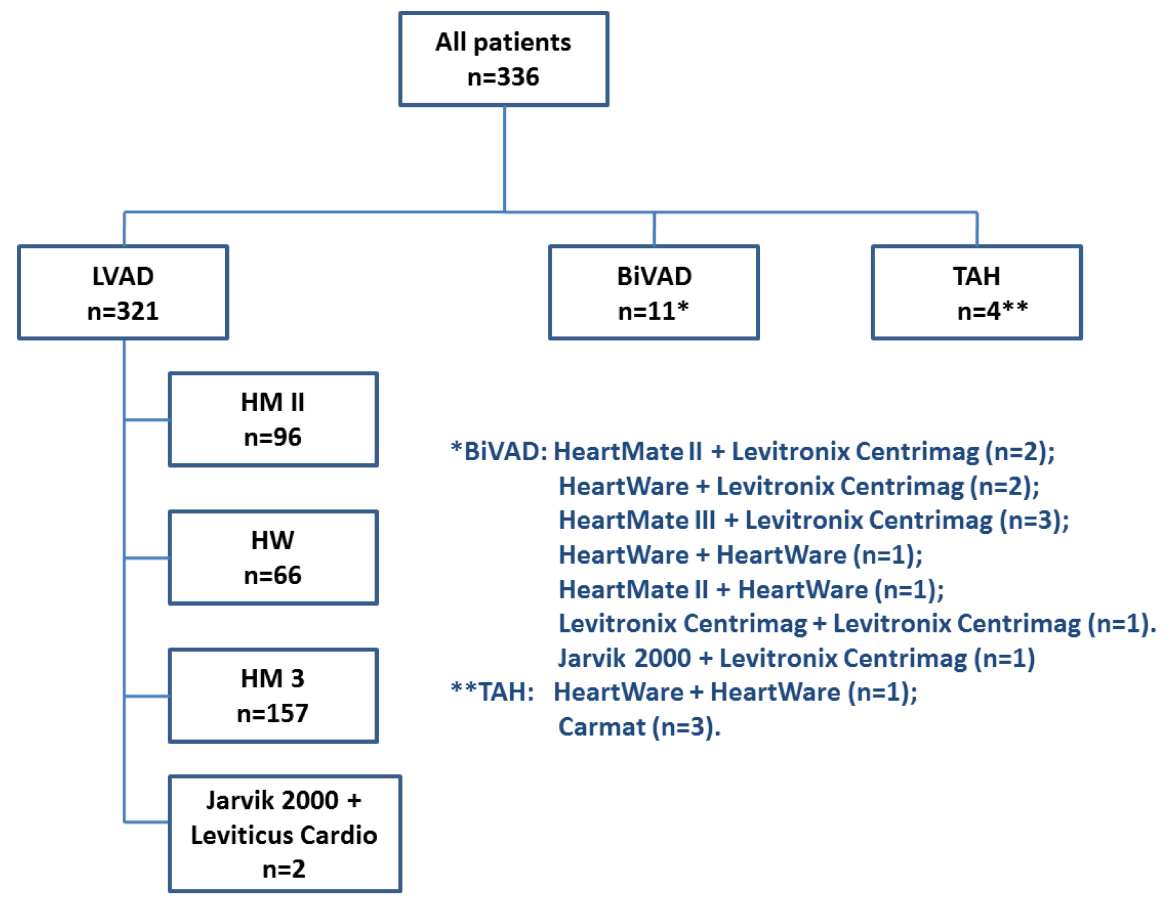




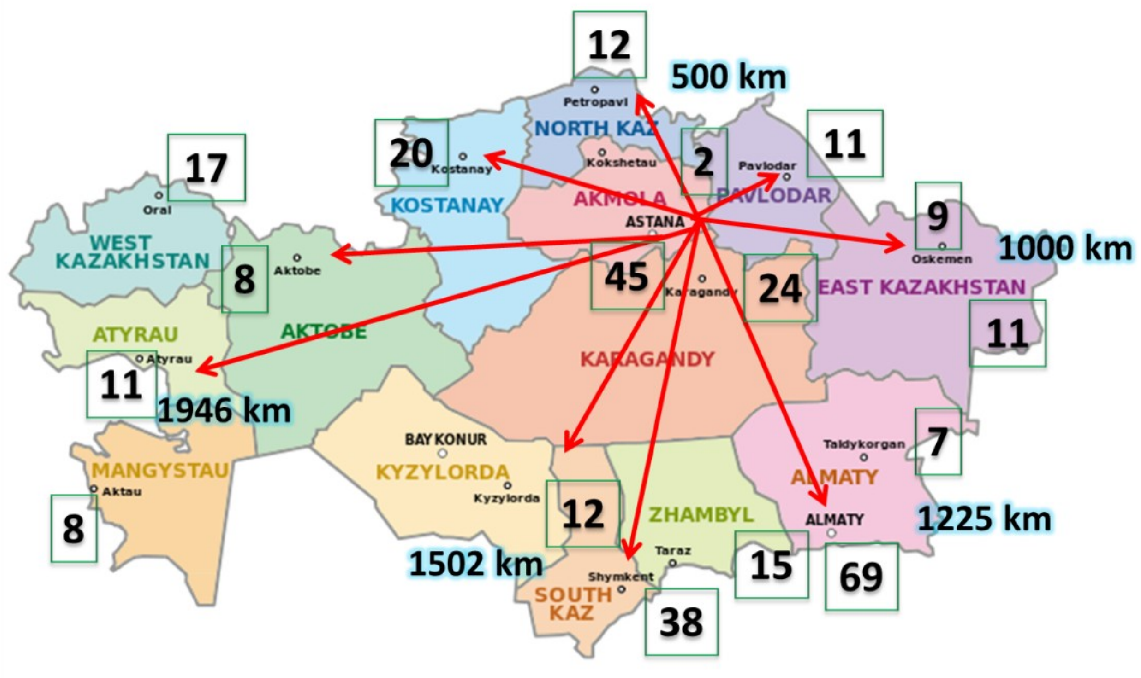




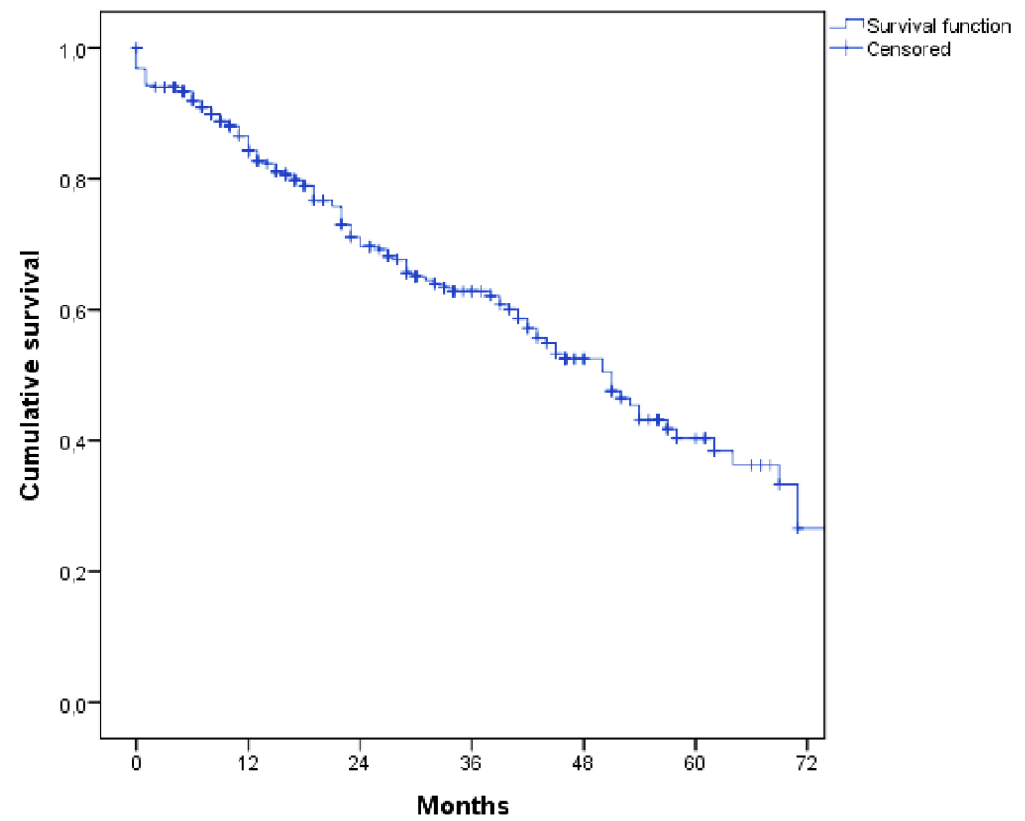

\begin{tabular}{|l|c|c|c|c|}
\hline Survival, \% & 1 year & 2 year & 3 year & 4 year \\
\hline LVAD patients & 84.3 & 69.7 & 62.8 & 52.5 \\
\hline
\end{tabular}




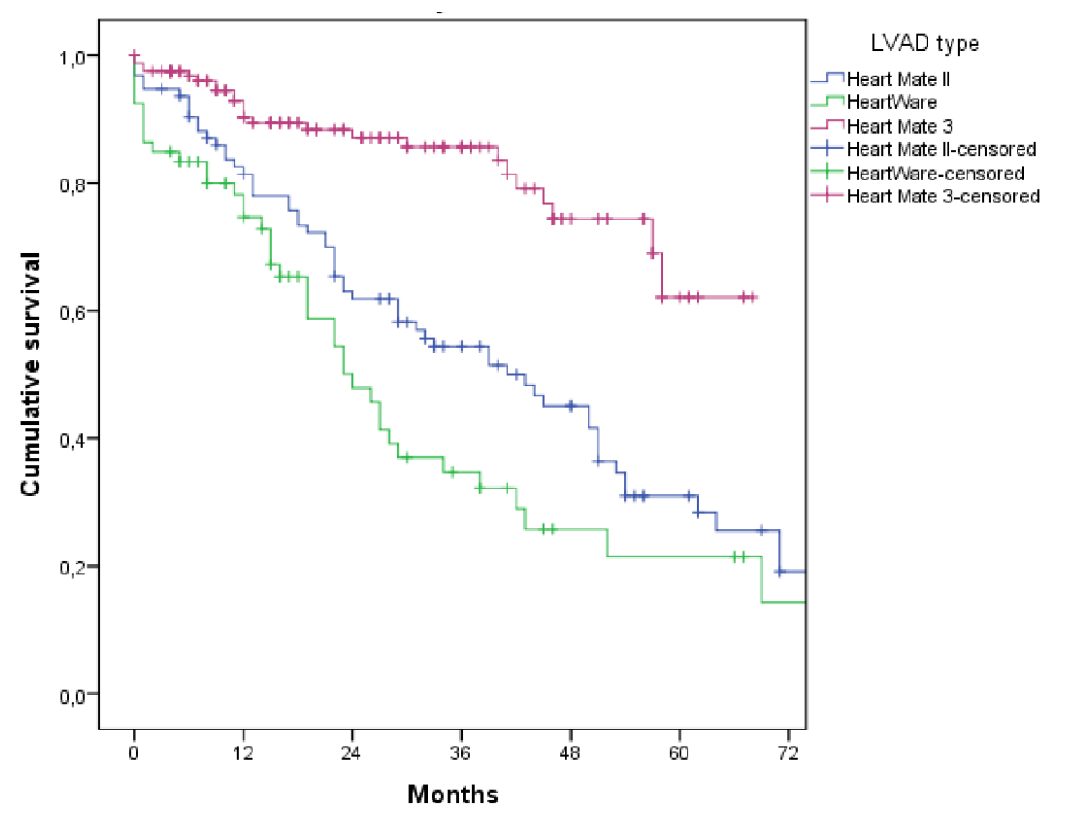

\begin{tabular}{|l|c|c|c|c|}
\hline Survival, \% & 1 year & 2 year & 3 year & 4 year \\
\hline HeartMate II & 81.4 & 61.8 & 54.4 & 46.7 \\
\hline HeartWare & 74.6 & 47.9 & 34.7 & 25.8 \\
\hline HeartMate 3 & 90.3 & 87.1 & 85.6 & 79.1 \\
\hline
\end{tabular}




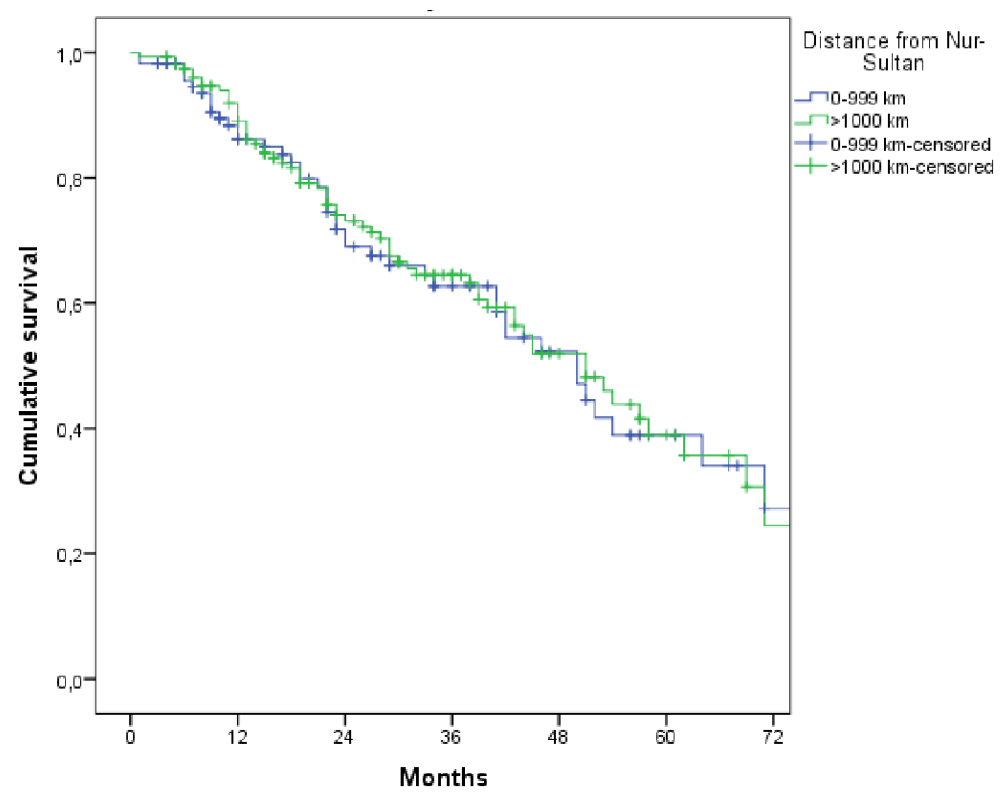

\begin{tabular}{|l|c|c|c|c|}
\hline Survival, \% & 1 year & 2 year & 3 year & 4 year \\
\hline$\leq 999 \mathbf{~ k m , ~} \mathbf{n = 1 3 8}$ & 86.2 & 69 & 62.7 & 54.5 \\
\hline $\begin{array}{l}\mathbf{1 0 0 0} \mathbf{~ k m}, \\
\mathbf{n = 1 8 3}\end{array}$ & 89 & 73.1 & 64.5 & 54.9 \\
\hline
\end{tabular}




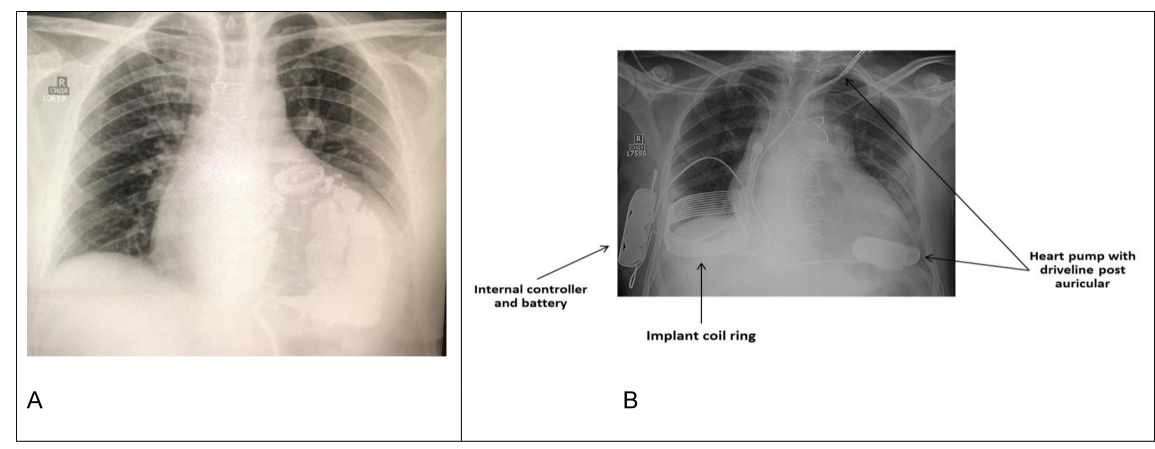

1 


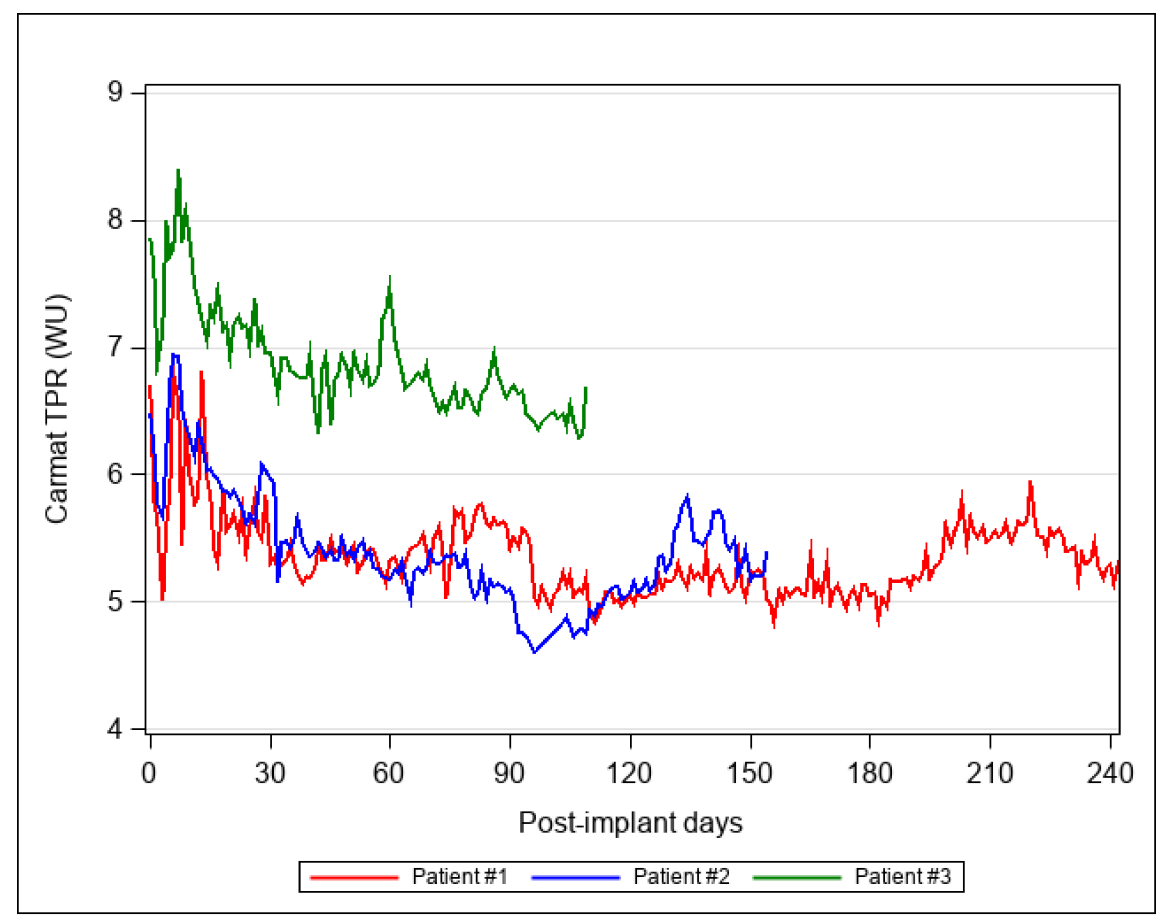

\section{Hosted file}

Table 1.pdf available at https://authorea.com/users/379860/articles/496077-mechanicalcirculatory-support-as-an-alternative-solution-in-circumstances-leading-to-a-shortageof-organ-donors

\section{Hosted file}

Table 2.pdf available at https://authorea.com/users/379860/articles/496077-mechanicalcirculatory-support-as-an-alternative-solution-in-circumstances-leading-to-a-shortageof-organ-donors

\section{Hosted file}


Table 3.pdf available at https://authorea.com/users/379860/articles/496077-mechanicalcirculatory-support-as-an-alternative-solution-in-circumstances-leading-to-a-shortageof-organ-donors 